\title{
Spotlight on Compulsive Sexual Behavior Disorder: A Systematic Review of Research on Women
}

This article was published in the following Dove Press journal:

Neuropsychiatric Disease and Treatment

\author{
Ewelina Kowalewska (D) \\ Mateusz Gola (D) 2,3 \\ Shane W Kraus (iD) 4 \\ Michal Lew-Starowicz (D) \\ 'Department of Psychiatry, Centre of \\ Postgraduate Medical Education, Warsaw, \\ Poland; ${ }^{2}$ Swartz Center for \\ Computational Neuroscience, Institute \\ for Neural Computations, University of \\ California, San Diego, CA, USA; ${ }^{3}$ Institute \\ of Psychology, Polish Academy of \\ Sciences, Warsaw, Poland; ${ }^{4}$ Department \\ of Psychology, University of Nevada, Las \\ Vegas, NV, USA
}

Purpose of Review: World Health Organization recently included compulsive sexual behavior disorder (CSBD) to the upcoming 11th edition of International Classification of Diseases (6C72). Despite the potential benefits of this decision (eg, the acceleration of research in the field will allow the development of effective treatments), previous research focused mainly on men, and as a result, we do not have an accurate clinical picture of compulsive sexual behavior (CSB) among women. Therefore, in this systematic review, we aim to present available knowledge on this topical subject. Literature search was conducted in the guideline of PRISMA methodology. Studies were identified from multiple databases including Academic Search Ultimate, SocINDEX, PsycARTICLES, PsycINFO, PubMed, and MEDLINE. Out of a total of 10,531 articles identified and screened, 58 were included in this review. Included studies covered the following topics: prevalence and etiology of CSB, behavioral and cognitive processes involved, comorbidities, personality traits, psychosocial and interpersonal difficulties, traumatic experiences, and treatments.

Recent Findings: Available studies indicate that CSB symptom severity is lower in women than in men. Overall, women reported consuming pornography less often than men and exhibit lower rates of feeling urges to these materials. CSB symptoms (including problematic pornography use) have been found to be positively related to trait psychopathy, impulsivity, sensation seeking, attention-deficit/hyperactivity disorder symptoms, obsessive-compulsive disorder, pathological buying, sexual dysfunctions, general psychopathology, child sexual abuse, while negatively related to dispositional mindfulness.

Summary: Conclusions that can be drawn from prior studies are considerably limited. There are no accurate estimates of the CSB prevalence or severity among women, and studies have been mostly conducted on non-clinical populations, which has limited application for women diagnosed with CSBD.

Keywords: compulsive sexual behavior, problematic pornography use, women

\section{Introduction}

Compulsive sexual behavior (CSB) such as excessive pornography use and masturbation, uncontrolled use of paid sexual services, and impulsive/compulsive engagement in risky sexual contacts, is an emerging topic in science and psychiatry. ${ }^{1}$ Research within the last decade has provided data showing some similarities of neuronal mechanisms underlying CSB (in men), and substance and behavioral addiction, ${ }^{2-9}$ proposed therapeutic interventions ${ }^{10-13}$ and conceptualization, ${ }^{14-18}$ what resulted with the inclusion of compulsive sexual behavior disorder (CSBD) in the 11th edition of the
Correspondence: Ewelina Kowalewska Department of Psychiatry,

Centre of Postgraduate Medical

Education, 99/103 Marymoncka St.,

Warsaw 0I-8I3, Poland

Email ewelina.kowalewska@cmkp.edu.pl 
International Classification of Diseases (6C72). ${ }^{19}$ According to ICD-11, CSBD is characterized by a persistent pattern of failure to control intense, sexual impulses or urges, resulting in repetitive sexual behavior over an extended period (eg, 6 months or more) that induces marked distress or impairment in personal, family, social, educational, occupational, or other important areas of functioning. ${ }^{15}$ Human sexuality is a complex phenomenon, containing biological, psychological, social, and cultural components. It encompasses various aspects of our being, such as attitudes and behaviors toward our sexual health as well as values, feelings, and experiences. Men and women differ in many aspects of their sexuality such as sexual reactivity ${ }^{20-22}$ and preferences. ${ }^{23,24}$ For example, gender differences (both intergroup and intragroup) are visible in the context of the sexual response cycle. The classic linear model of four consecutive stages (excitation, plateau, orgasm, resolution) $)^{25}$ better describes the male sexual response cycle, while a greater variability of the female sexual response led researchers to the introduction of a different circular model. ${ }^{26,27}$ Due to these peculiarities in the male/female sexual response cycle, one can also expect gender differences in the CSBD-related features.

Despite the body of research regarding CSB on men, there are little data on these behaviors among women. The focus on men was based on the agreement among researchers that CSB is substantially more frequent among men than women. ${ }^{28-30}$ According to available statistics, CSB affects from $3 \%$ to $6 \%$ of people in the United States. ${ }^{31-34}$ The precise prevalence estimates of CSB for women remain uncertain, but available studies thus far including both women and men report a proportion of $8 \%$ to $40 \%$ female. ${ }^{29}$ The wide discrepancy in prevalence rates of CSB in women likely reflects the use of imprecise measurement instruments. Perhaps the best estimation of CSB among women comes from the DSM-5 field trial (which is controversial due to the lack of evidence of its conduct $^{35}$ ). Researchers found that $5.3 \%$ of total samples of specialized outpatient clinics patients who seek treatment for CSB were women. ${ }^{36}$ Most recent data on pornography use collected on representative samples in the United States of America (USA) ${ }^{14}$ and Poland ${ }^{37}$ show that approximately $11 \%$ of adult men and $3 \%$ of women consider themselves to some extent "addicted to pornography".

Previous research indicates that among men the dominant clinical presentation of CSB is problematic pornography use usually coupled with masturbation..$^{28,36,38,39}$ Given the paucity of science, we do not have an accurate clinical picture of what CSB looks like in women. This systematic review aims to summarize the current state of knowledge about CSB among women and to critically analyze the strengths and weaknesses of the current research findings. Further, through this process, we will accomplish three goals: 1.) identify key differences in clinical picture of CSB between men and women, 2.) formulate practical implications (eg, for diagnosis, therapy, prevention) for clinical work with women, and 3.) generate directions for future research. For the present work, we use Compulsive Sexual Behavior (or CSB) to refer to out-of-control or dysregulated sexual behavior patterns, despite past literature's use of such terms as sexual addiction, compulsive sexual behavior, hypersexuality, and similar terms. The research described later in this review comes from the period before CSBD criteria were established, and the term CSB in this review refers to symptoms (often understood according to various conceptualizations - sex addiction, sexual compulsivity, etc.) rather than a clinical diagnosis consistent with the operationalized criteria.

\section{Methodology \\ Search Strategy}

This systematic review was conducted in accordance with the Preferred Reporting Items for Systematic Reviews and Meta-Analyses (PRISMA) guidelines. ${ }^{40}$ To identify studies examining CSB among women we searched for articles using multiple databases including Academic Search Ultimate, SocINDEX, PsycARTICLES, PsycINFO, PubMed, and MEDLINE. Our search included the following terms: (compulsive sexual behavior* OR hypersexual* OR pornography OR porn OR sexually explicit materials OR compulsive masturbation OR excessive masturbation OR masturbation) AND (women OR woman OR females OR female). The electronic databases were searched for titles or abstracts containing these keywords in published articles between January 1, 2015, and December 31, 2019.

\section{Inclusion Criteria}

We excluded articles if they: (1) were not published in the past 5 years, (2) were not scientifically peer-reviewed, (3) were not published in English, (4) did not present empirical data, (5) were not collected from humans, (6) did not assess compulsive sexual behaviors, and (7) did not present separate results on females. Of 10,531 articles found, 58 papers 
were included in the final review. Details concerning the method of literature search are shown in Figure 1.

\section{Results}

\section{Outcomes of Interest}

The analysis of selected articles indicated several themes that were explored by the researchers in their studies on CSB in women. These themes included prevalence and concept of CSB, behavioral and cognitive processes involved, comorbidities, personality traits, psychosocial and interpersonal difficulties, traumatic experiences, and treatments.

\section{Prevalence and Concept of CSB}

Although no large epidemiological studies on CSB in women have been performed yet, some research suggests that part of the female population experience problems related to CSB. ${ }^{14,41-63}$ However, none of these studies verified how many of them met CSBD diagnostic criteria.

In a cross-sectional study conducted by Baranowski and colleagues, ${ }^{41} 3 \%$ of a sample of German women aged 18-77 years reported problematic pornography use
(PPU; considered by them as a loss of control over the time spent on pornography and feeling craving for these materials), which was further associated with the amount of time spent viewing pornography, and also greater sexual motivation and emotional avoidance. Another crosssectional study by Rissel and colleagues with 10,131 Australian women aged 16 to 69 years showed that $41 \%$ of participants reported watching pornographic material in the past year, and $1 \%$ of them self-identified as "addicted to pornography" based on subjective feeling. ${ }^{42}$ These results are comparable to Grubbs and colleagues ${ }^{14}$ investigation conducted on a cross-sectional US nationally representative sample of 1059 women and 1016 men, showing that $3 \%$ of women and $11 \%$ of men reported some agreement with the statement "I am addicted to pornography", and $1 \%$ of women and $3 \%$ of men agreed with this statement strongly. Results of a study of Daspe and colleagues involving 1036 Canadian participants (565 women) aged 18-55 demonstrated a positive relationship between the frequency of pornography use and perceived lack of control for women and men. ${ }^{43}$

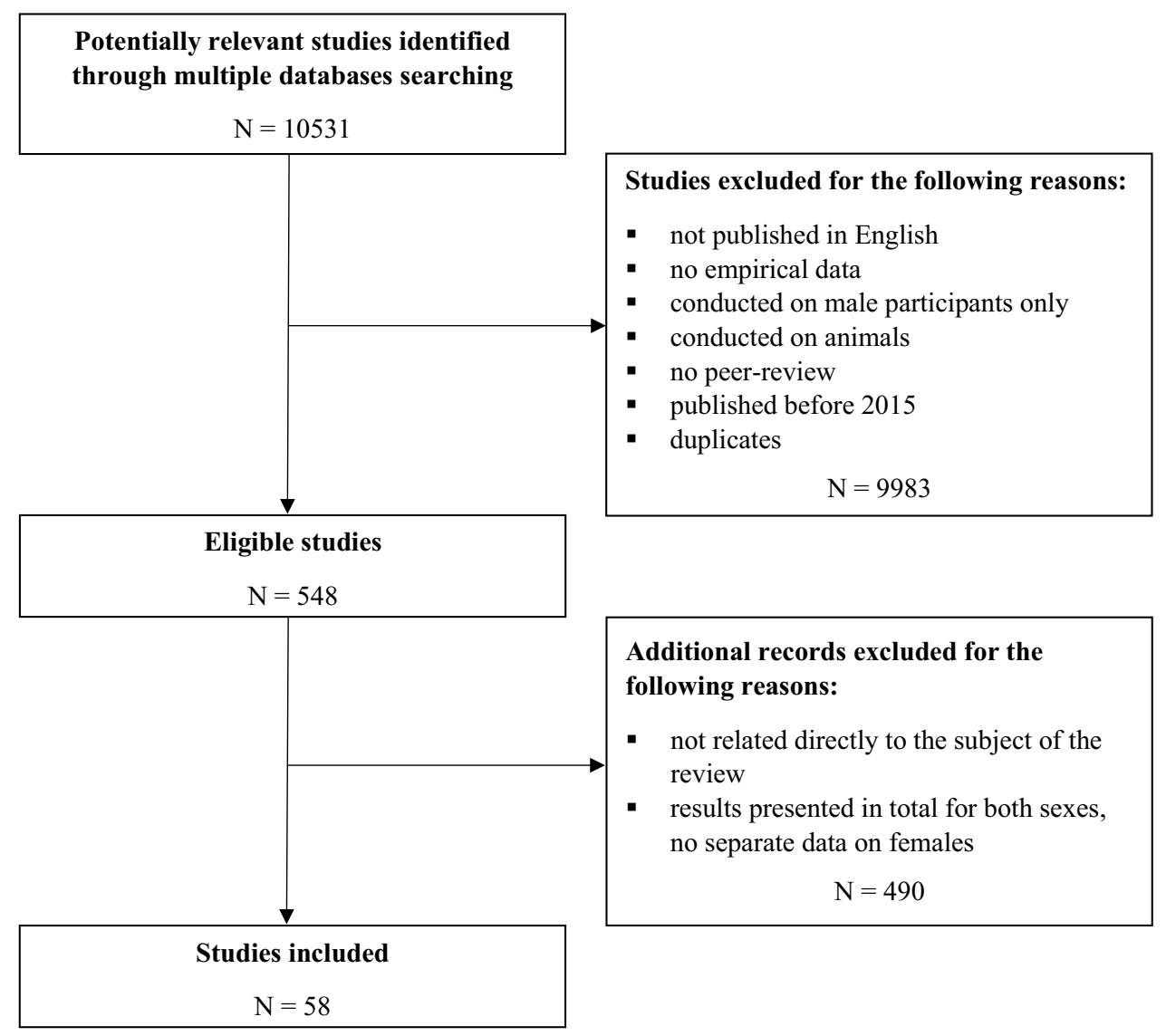

Figure I Literature review process. 
A French cross-sectional study of Blais-Lecours and colleagues, conducted on a community sample of 597 women and 235 men aged 18-78 years, revealed that $51 \%$ of women and $90.2 \%$ of men declared consuming cyberpornography. ${ }^{44}$ Moreover, using The CyberPornography Use Inventory (CPUI), ${ }^{64}$ authors found that women (as compared to men) reported less pornography time use, perceived compulsivity to pornography, sexual compulsivity, and efforts to access cyberpornography. According to the results of Weinstein and colleagues ${ }^{45}$ investigation conducted on a group of 192 Israeli men and 75 women, women exhibited lower rates of feeling urges to pornography and frequency of cybersex compared to men.

A study of Harper and Hodgins involving Canadian university students (105 women and 86 men) showed less frequent pornography use and later age of pornography exposure among women (as compared to men). ${ }^{46}$ Also, women were less likely to self-identify as addicted to pornography and obtained lower scores on the $\mathrm{CPUI}^{64}$ as well as the internet pornography addiction criterion questions (IP-CRIT), which have been adapted by researchers from DSM-5 preliminary set of criteria for diagnosing Internet Gaming Disorder. ${ }^{65}$

A North American cross-sectional study of Vaillancourt-Morel and colleagues ${ }^{47}$ assessing dimensions of cyberpornography indicated three distinct profiles of users - recreational, highly distressed but noncompulsive, and compulsive. The recreational profile, which consisted of a larger proportion of women (486 of 596 women aged $18-78$ years) and dyadic users who spent a moderate amount of time viewing pornography, reported lower levels on three dimensions of PPU - compulsivity, efforts to access pornography and emotional distress associated with its consumption. Moreover, results taken from a Ballester-Arnal and colleagues' cross-sectional study ${ }^{48}$ conducted on a sample of 1557 Spanish college students between 18 and 25 years of age found that $96.9 \%$ of total female sample were recreational users and only $1.7 \%$ risky users (spending between 1 and $10 \mathrm{~h}$ on cybersex). ${ }^{66}$

In addition to research focusing solely on PPU, some studies have been found on CSB more broadly. Dickenson and colleagues' results of the population-based American National Survey of Sexual Health and Behavior ${ }^{49}$ involving 1174 women and 1150 men aged 18-50 years revealed that $7 \%$ of women and $10.3 \%$ of men scored 35 or higher in Compulsive Sexual Behavior Inventory, ${ }^{67}$ which indicates a high probability of meeting diagnostic criteria of CSBD. ${ }^{19}$

In an Australian study of Walton, Cantor, and Lykins ${ }^{50}$ using Hypersexual Behavior Inventory (HBI-19), ${ }^{68} 31$ women (18.4\% of total sample) and 63 men exhibited clinically significant hypersexual behavior based on Reid and colleagues' suggested cut-off score $(\geq 53)$, and results of a cross-sectional study of Kraus and colleagues ${ }^{51}$ conducted on a sample of 820 post-deployed US military veterans revealed that fewer women $(4.3 \%)$ than men $(13.8 \%)$ demonstrated symptoms related to CSB.

Engel and colleagues' cross-sectional study ${ }^{52}$ examining individual characteristics and signs of coercive sexual behavior conducted on a large German-speaking population of 564 women and 630 men showed that women levels of CSB symptom severity (measured accordingly to criteria of hypersexual disorder [HD] proposed by Kafka in $2010^{28}$ ), pornography use, masturbation, and engaging in partnered sex were lower among women than men. $13.1 \%$ of women and $45.4 \%$ of men obtained scores indicating a high level of CSB symptoms severity as assessed by HBI-19 questionnaire. ${ }^{68}$ Furthermore, $18 \%$ of women (compared to $59 \%$ of men) reported fantasies of sexual coercion, and $4 \%$ of women (compared to $20 \%$ of men) declared behaviors involving sexual coercion toward others, which turned out to be associated with CSB symptoms. Importantly, the connection of total sexual outlet as well as pornography consumption was more strongly related to the level of CSB symptom severity in women than in men. The authors also found that $61 \%$ of women from the examined sample reported at least moderate symptoms of depression (assessed by Patient Health Questionnaire), ${ }^{69}$ and that depressive symptoms were positively associated with levels of CSB symptom severity (as measured by HBI-19) ${ }^{68}$ among women and men.

Lower prevalence of CSB symptoms among women than men was also found in a Böthe and colleagues' crosssectional study ${ }^{53}$ on a large, diverse, non-clinical sample of 6132 women and 11,902 men using HBI- $19^{68}$ questionnaire. Gender and Sexual Orientation-Based Comparisons showed that LGBTQ (lesbian, gay, bisexual, transgender, and queer) men scored the highest on each HBI-19 subscale, ${ }^{68}$ while heterosexual women scored the lowest. Moreover, LGBTQ men had the highest outcomes on other indicators of CSB, such as frequency of masturbation, number of sexual partners, or frequency of pornography use. In turn, LGBTQ women had the highest scores on the subscale related to coping with unwanted feelings and 
stress. Similar results have been shown in a study of Tripodi and colleagues conducted on two non-clinical Italian and Swedish samples consisting of 433 women and 414 men aged $20-30$ years. ${ }^{54}$ Women spent less time on online sexual activities (including pornography viewing) as well as scored lower on instruments measuring problematic cybersex behavior (Internet Sex Screening Test$^{70}$ and sexual compulsivity (Sexual Addiction Screening Test-Abbreviated). ${ }^{70}$

Results from a study by Mulhauser, Short, and Weindtock ${ }^{55}$ conducted on a group of 134 women and 235 men above the age of 18 from the US general population showed gender differences in scores obtained on measures of $\mathrm{CSB}$, such as HBI- $19,{ }^{68}$ Pornography Consumption Inventory (PCI), ${ }^{71}$ CPUI, ${ }^{64}$ and Problematic Pornography Use Scale (PPUS), ${ }^{72}$ with women scoring significantly lower than men.

Among 216 addicted (to alcohol, drugs, gambling, or sex) participants from a study of Zilberman and colleagues ${ }^{56}$ carried out on Israeli sample, 57 men and 4 women exhibited high levels of CSB symptom severity, as assessed by the Individual-Based Compulsive Sexual Behavior Scale (I-CSB). ${ }^{73}$ Lower scores among women (as compared to men) on the $\mathrm{I}_{-} \mathrm{CSB}^{73}$ were also observed in a study by Efrati on a group of 310 high school Israeli adolescents (127 teen girls) aged $16-18 .^{57}$

Some research that has been found during the selection process focused on the concept of CSB. Werner and colleagues' study ${ }^{58}$ on a Croatian sample of 1786 women and 1242 men aged 18-60 years, testing the concept of CSB from a perspective of network analytic approach to psychopathology ${ }^{74}$ assuming that CSB symptoms and related behaviors are represented as inter-connected nodes, revealed similar structure for women and men. For both women and men, the central positions in the networks were occupied by psychological distress and sexuality-related negative emotions (eg, depression, anxiety, shame), along with a loss of control over sexual feelings (eg, pleasure, desire). Interestingly, pornography use was positioned peripherally regardless of gender, but in women, the relationship between pornography use and shame was present.

Additionally, another two studies sought to answer a question of whether CSB may be best represented dimensionally or categorically, determined the latent structure of a construct using taxometric methods. Analyses of Graham and colleagues' study was performed on a group of 1112 US individuals (53.6\% women), while a study of
Kingston and colleagues involved 915 Canadian individuals (671 women). Results from both studies were indicative of the dimensionality of CBS in the case of women. ${ }^{59,60}$

Carvalho and colleagues, ${ }^{61}$ in a study exploring the overlap between problematic sexuality and high sexual desire, conducted on a Croatian non-clinical sample of 4597 men and women aged 18-60 years (age over 18 was the only inclusion criterion), extracted two clusters. Cluster one, named "control/consequences cluster", represents a lack of control over one's sexuality and negative outcomes, while the other cluster, named "desire/activity cluster", reflects the high sexual desire and frequent sexual activity. Authors found that women included in the "control/consequences cluster" showed a higher level of depression and neuroticism, and they reported more often co-existing the consequences of substance abuse (such as feeling guilty, neglecting of duties, forgetfulness of facts that happened under the influence) than women in "desire/ activity cluster". In turn, Štulhofer and colleagues ${ }^{62}$ examining a combination of CSB (according to HD criteria) ${ }^{28}$ and high sexual desire on a group of 2599 Croatian women aged 18-60, found that 178 women from the studied sample were classified in the high sexual desire group, 239 women - in the hypersexuality group, and 57 women met criteria for both groups. Furthermore, high sexual desire and high sexual desire and hypersexuality groups reported more negative consequences related to their sexuality.

Gender differences were also found in studies of Efrati and Gola ${ }^{63}$ on a sample of 1800 Israeli adolescents (841 teen boys and 959 teen girls aged 14-18 years). The authors, using a latent profile analysis, revealed three clusters of CSB: abstainers, sexual fantasizers, and individuals with CSB (based on criteria of HD). ${ }^{28}$ Teen girls were more likely included in a group of abstaining adolescents, characterized by low scores in all subscales of the I-CSB ${ }^{73}$ such as sexual fantasies, obsessive sexual thoughts, and spending more time watching pornography.

\section{Behavioral and Cognitive Processes}

Our search also revealed three articles describing attentional biases to sex-related stimuli, ${ }^{75-77}$ which are understood as unconscious processes that lead individuals to focus and sustain attention on addiction-relevant cues in their naturalistic environment. ${ }^{78,79}$ According to incentive sensitization theory by Robinson and Berridge, ${ }^{80}$ addicted individuals exhibit fast shifts of attention to stimuli related 
to their addiction (eg, alcohol), because of the cue's incentive salience.

Pekal and colleagues ${ }^{75}$ conducted a study on a group of 174 participants aged $18-52$ years (87 females) to investigate the role of attentional biases in the development of excessive and addictive usage patterns of internet pornography. Tendencies toward uncontrolled use of internet pornography were assessed by the ShortInternet Addiction Test adapted to online sexual activities (s-IATsex), ${ }^{81}$ while attentional bias was measured using the Visual Probe Task. ${ }^{82}$ Women (as compared with men) had lower mean scores in s-IATsex and - based on cutoff scores - the sample consists of two problematic female users. In addition, women exhibited lower attentional biases toward sexual cues compared to men. The results of this investigation also revealed a relationship between attentional bias and symptom severity of the addictive use of pornography. Although women and men differ in reaction times to pornographic stimuli, the analysis showed that attentional biases occur independently of sex within the framework of excessive pornography use symptoms.

An Albery and colleagues' study ${ }^{76}$ using a modified Stroop task did not show gender differences in attentional biases for sex-related words among 55 sexually active individuals (28 male and 27 female aged 20-69). Regardless of gender, among participants with a higher level of sexual compulsivity assessed by the Sexual Compulsivity Scale (SCS), ${ }^{83}$ greater attentional bias was linked with lower levels of sexual experience. In turn, among those with a low level of sexual compulsivity, levels of sexual experience did not differentiate the levels of attentional bias. These findings indicated that attentional preference for concern-related stimuli might be dependent on the interaction between time to remain sexually active and the level of sexual compulsivity.

The third study, conducted on a group of 47 women and 48 men by Stark and colleagues, ${ }^{77}$ demonstrated that symptoms of internet PPU (assessed by s-IATsex) ${ }^{81}$ and daily time spent on watching these materials were less pronounced in women than in men. In addition, they found a linear relationship between the approachavoidance score towards pornography (measured by Approach-Avoidance Task) and internet PPU among women and men, which indicated that participants characterized by greater problems while adjusting for the internet pornography consumption was associated with only approach biases for pornography.

\section{Comorbidity and Predisposing Factors}

Identified studies were focused on the relationship between CSB and substance-use disorders, ${ }^{84-88}$ compulsive buying disorder or compulsive buying behavior, ${ }^{89-91}$ ADHD, ${ }^{92}$ obsessive-compulsive disorder, ${ }^{93}$ Parkinson's disease, ${ }^{94}$ borderline personality disorder, ${ }^{95}$ and autism spectrum disorder. ${ }^{96}$

Brem and colleagues ${ }^{84-86}$ in the three articles described their studies conducted on groups of adults in residential treatment for substance-use disorders (SUDs). In the first study, the authors examined dispositional mindfulness as a potential protective factor for CSB on a group of 446 women (at least 18 years old) diagnosed with one or more SUDs. ${ }^{84}$ Dispositional mindfulness is defined as a tendency to have open and receptive awareness and attention towards present moment experiences. ${ }^{97}$ The results of this investigation showed a negative relationship between dispositional mindfulness and CSB among women with SUDs. After adding dispositional mindfulness as a predictor, alcohol problems (not drug problems) proved to be a significant predictor of CSB among women. Furthermore, 53.2\% of women reported at least one concern with CSB, gaining 1 point out of 20 on the Sexual Addiction Screening Test-Revised (SAST-R), ${ }^{98}$ and $12.6 \%$ of a sample scored six or higher on the SAST-R, thus being within the at-risk range of CSB. Results of the second investigation ${ }^{85}$ carried out on 446 women in residential treatment for SUDs showed a positive relationship between CSB symptoms and defectiveness/shame, PTSD symptoms, and alcohol/drug use and problems. Furthermore, experiential avoidance defined as a tendency to avoid, escape, or change one's experience of aversive internal events (eg, thoughts, feelings), ${ }^{99}$ was positively related to CSB symptoms, PTSD symptoms, defectiveness/shame, and drug use and problems. Finally, the relationship between PTSD symptoms, defectiveness/ shame, and CSB symptoms may be partially explained by experiential avoidance. In the third study, ${ }^{86}$ Brem and colleagues using the same methods examined gender differences in the relationship between CSB and dispositional mindfulness on a large group of 1993 adults (22.4\% female) in residential treatment for SUDs. For women with SUDs, results revealed negative relationships between CSB indicators (assessed by SAST-R) ${ }^{98}$ and two dimensions of dispositional mindfulness - acting with awareness and non-judging of inner experience. Moreover, two SAST-R subscales - affect disturbance 
and preoccupation - have been found to be negatively associated with alcohol use and problems, but positively associated with drug use and problems. In addition, three SAST-R dimensions - internet problems, preoccupation, and relationship disturbance - were positively related to depression symptoms among women.

Another set of studies on a group of women and men admitted to a 12-step-based private, residential treatment program for SUDs have been conducted by Elmquist and colleagues. $^{87,88}$ The first one, ${ }^{87}$ which involved 120 women, showed that after adjusting for alcohol/drug use and problems, age, and positive impression management, CSB symptoms were positively associated with borderline personality symptoms. The second study, ${ }^{88}$ conducted on a sample of 198 men and 62 women, revealed that five early maladaptive schemas domains (disconnection and rejection, impaired autonomy and performance, otherdirectedness, impaired limits, over vigilance and inhibition) assessed by the Young Schema Questionnaire - Long Form, Third Edition (YSQ-L3) ${ }^{100}$ were positively associated with CSB symptoms assessed by SAST-R $^{98}$ in a group of individuals with SUDs. No gender differences were found between CSB and non-CSB groups.

Using a Brazilian sample, de Mattos, Kim, and Requião examined psychiatric co-morbidities in compulsive buying disorder (CBD) on a group of 151 women and 20 men with CBD and found that women were less likely to be diagnosed with sexual addiction. ${ }^{89}$ However, it is worth emphasizing that drawing strong conclusions about gender in the context of co-occurrence of CBD and CSB on such a small sample of men is unwise. Müller and colleagues $^{90}$ examined the risk for exercise dependence, eating disorder pathology, and other addictive behaviors among 128 fitness centers clients (28.3\% females). The authors found a positive relationship between CSB symptoms (assessed by HBI-19) ${ }^{68}$ and symptoms of pathological buying (assessed by Compulsive Buying Scale) ${ }^{101}$ in both women and men. In addition, women exhibited fewer symptoms of CSB as compared to men. Finally, an investigation of Granero and colleagues ${ }^{91}$ focused on compulsive buying behavior (CBB) and CBD comorbidity involved a sample of 3324 patients divided into five groups according to their diagnosis: CBB ( $\mathrm{n}=110 ; 71.8 \%$ females), sexual addiction ( $n=28 ; 3.6 \%$ females), internet gaming disorder ( $\mathrm{n}=51 ; 5.9 \%$ females), internet addiction ( $n=41 ; 26 \%$ females), and gambling disorder $(n=3094$; $10.1 \%$ females). Overall, they found that the combination of impulsive/compulsive symptoms was particularly visible in patients with $\mathrm{CBB}$ and sexual addiction.

To identify possible similarities and differences in the relationship between $\mathrm{ADHD}$ and $\mathrm{CSB}$ (according to HD ${\text { criteria })^{28} \text { and PPU, Böthe and colleagues }}^{92}$ conducted a study on a large, non-clinical sample of 4237 women and 9806 men. Among women, CSB was found to be positively associated with PPU and ADHD symptoms, while PPU was weakly associated with ADHD symptoms. As interpreted by the authors, results suggest that among women ADHD symptoms would lead to CSB rather than to PPU.

Fuss and colleagues $^{93}$ examined the association between CSB and obsessive-compulsive symptoms on a sample of 279 women and 260 men aged 18-75 years. Fuss and colleagues found that in patients with current OCD a lifetime prevalence of CSBD was 5.6\%, and significantly lower in women than men. In turn, El Otmani and colleagues ${ }^{94}$ conducted a study on 125 patients diagnosed with Parkinson's disease to determine the prevalence of current impulse control disorders (ICDs) among this group. Results of an analysis using Questionnaire for Impulsive-Compulsive Disorders in Parkinson's Disease Rating Scale ${ }^{102}$ identified ICDs in $28 \%$ of patients (15 women and 20 men), of which 2 women and 8 men reported CSB symptoms.

Another study by Jardin and colleagues, ${ }^{95}$ conducted on a group of 1326 female college students showed that sexual compulsivity (as assessed by HBI-19) ${ }^{68}$ may mediate the influence of borderline personality disorder features on a number of sexual partners, suggesting that women suffer from BPD may be more susceptible to the development of CSB symptoms. Lastly, a study of Schöttle and colleagues ${ }^{96}$ revealed that patients with autism spectrum disorder (90 patients with Asperger syndrome and 6 with atypical autism) reported CSB (as assessed by HBI$19)^{68}$ more frequently than those without autism spectrum disorder. However, these differences occurred only in male patients, and not among female patients.

\section{Personality Traits}

The contribution of personality factors to ratings of CSB symptoms was examined in 10 studies. $^{77,103-110}$

In a study of Shimoni and colleagues, ${ }^{103} 81$ women and 186 men were recruited via internet sites used for finding sexual partners. Results of this investigation showed that women (as compared to men) obtained lower scores on Sexual Addiction Screening Test 
(SAST),${ }^{111}$ they were less open to experiences and more neurotic (as assessed by the Big Five Index). ${ }^{112}$ Interestingly, higher neuroticism was related to higher scores on the SAST but only in men.

In the case of trait impulsiveness and compulsiveness, Böthe and colleagues ${ }^{104}$ investigated its relation to PPU and CSB symptoms on a large community sample of 13,778 individuals (4151 females). Regardless of gender, PPU was weakly associated with impulsivity and compulsivity. Additionally, impulsivity was more strongly related to CSB than compulsivity. Analysis of the female sample model revealed that both traits were positively but weakly related to PPU, compulsivity was positively and weakly associated with CSB, and impulsivity was positively and moderately associated with CSB. Rømer and colleagues ${ }^{105}$ using regression analyses assessed the relationship between impulsivity traits and indicators of addictionrelated behaviors on a group of 109 individuals aged 16-26 years (31\% females) from a Danish nationally representative survey. It has been found that after adjusting for gender, age and education, lack of perseverance - the UPPS-P Questionnaire ${ }^{113}$ factor - was associated with PPU; however, women had significantly lower scores on the Pornography Craving Questionnaire (PCQ) ${ }^{114}$ compared to men. Finally, a study of Carvalho and colleagues ${ }^{106}$ conducted on a non-clinical sample of 235 female college students showed that motor/planning impulsiveness (assessed by the Barratt Impulsiveness Scale), ${ }^{115}$ negative affect (assessed by the positive and negative affect schedule; PANAS), ${ }^{116}$ and psychoticism (assessed by the Brief Symptom Inventory) ${ }^{117}$ significantly predicted sexual compulsivity in women. It is worth emphasizing that only $2.5 \%$ of women from this sample presented clinically relevant levels of sexual compulsivity as assessed on the SCS. ${ }^{83}$

Two studies by Sindermann and colleagues ${ }^{107}$ examined an association between specific forms of internet-use disorder and "the dark triad of personality" (measured by the Short Dark Triad Questionnaire) ${ }^{118}$ on a group of 940 individuals (667 females). Results indicated that among women (but not among men), trait psychopathy was significantly positively correlated with tendencies toward problematic internet-pornography use (measured by s-IATsex). ${ }^{81}$

Another factor raised in scientific research on CSB was sexual sensation seeking. ${ }^{108,109}$ Burri $^{108}$ examined an association between sexual sensation seeking (measured by Sexual Sensation Seeking Scale), ${ }^{119,120}$ sexual compulsivity (measured by SCS) ${ }^{83}$ and gender identity, and sexual functioning (in female sample measured by the Female Sexual Function Index), ${ }^{121}$ on a population sample of 193 women and 86 men. Burri found that sexual sensation seeking was positively correlated with sexual compulsivity in women and men. Moreover, higher levels of sexual sensation seeking were related to higher levels of desire, arousal, lubrication, and orgasm and lower sexual pain among women. In turn, Chen and colleagues ${ }^{109}$ carried out a study on a group of 808 Chinese college students aged $17-22$ years $(42.3 \%$ female $)$ to test a model that sexual sensation seeking may impact PPU through online sexual activities, and that this relationship may be further influenced by the third-person effect (understood as a tendency to overestimate the influence that media has on the attitudes and behaviors of others while underestimating its impact on oneself ${ }^{122}$ ). In addition to the results showing that women scored lower on measures of online sexual activities and PPU, authors also found that this moderated mediation model accounted for a lower variance among women than men.

Stark and colleagues' investigation, ${ }^{77}$ aforementioned in the Behavioral and cognitive processes section, further demonstrated that greater trait sexual motivation, defined as a general motivation to be sexually active in a longlasting perspective, was related to higher problematic internet sexually explicit material use, which may indicate that this trait is a vulnerability factor for CSB. In turn, a study of Carvalho and Nobre ${ }^{93}$ conducted on a group of 260 female college students demonstrated that sexually aggressive women presented significantly higher levels of sexual compulsivity (assessed by SCS). ${ }^{83}$

\section{Psychosocial and Interpersonal Difficulties}

Some research, including those described in the previous sections, assessed the relationship between CSB and general psychopathology and sexual functioning, ${ }^{123}$ sexual satisfaction, ${ }^{43}$ sexting behaviors, ${ }^{124}$ forming intimate relationship, ${ }^{45}$ attachment, ${ }^{125}$ sexual orientation, ${ }^{125}$ and sexual excitation/inhibition. ${ }^{126}$

The results of an Italian study by Castellini and colleagues, ${ }^{123}$ conducted on a non-clinical sample of 532 women and 243 men showed that sexual dysfunctions (in women assessed by the Female Sexual Function Index), ${ }^{121}$ as well as general psychopathology (assessed by The Symptom Checklist [SCL]-90-Revised), ${ }^{127}$ were 
associated with CSB symptom severity (assessed by Hypersexual Disorder Screening Inventory) ${ }^{128}$ in both women and men.

In the case of sexual satisfaction, Daspe and colleagues $^{43}$ found that gender, length of the relationship, and parenthood did not moderate the interaction between frequency of pornography use and relationship and sexual satisfaction in the prediction of perceived lack of control over pornography viewing.

Another study of Morelli and colleagues, ${ }^{124}$ conducted on a sample of 610 adolescents aged 13-20 years $(63 \%$ teen girls) revealed gender differences regarding sexting behaviors (measured by The Sexting Behaviors Questionnaire) ${ }^{129}$ and cyberpornography addiction (measured by CPUI), ${ }^{64}$ with teen girls showing lower means in these variables. Furthermore, sexting behaviors were correlated with alcohol consumption and pornography use among both teen boys and girls.

According to results of Weinstein and colleagues study, ${ }^{45}$ in women, no correlation was found between ratings of difficulties in intimacy (assessed by the Questionnaire on difficulties in intimacy $)^{130}$ and cybersex (assessed by the Cybersex Addiction Test), ${ }^{131}$ whereas an association between pornography ratings (assessed by the Pornography Craving Questionnaire) ${ }^{132}$ and cybersex occurred on a trend level. In men, positive correlations have been found in both cases.

Another study of Weinstein and colleagues, ${ }^{125}$ conducted on a group of 50 women and 50 men over 18 years old, showed that both anxious and avoidant attachment were positively correlated with sexual compulsivity in all participants. Moreover, the analysis revealed a significant gender by sexual orientation interaction effect on sexual compulsivity. Specifically, lesbian women reported higher levels of sexual compulsivity compared to heterosexual women. No significant difference was found in the case of men regardless of sexual orientation.

Rettenberger, Klein, and Briken ${ }^{126}$ investigating the relationship between CSB (assessed by HBI-19), ${ }^{68}$ sexual excitation and sexual inhibition (assessed by the SIS/SESShort Form) ${ }^{133}$ on a group of 988 women and 750 men aged 18-62, found that women scored lower than men on a scale measuring sexual excitation (SES) and HBI-19, ${ }^{68}$ however, they obtained higher scores on both sexual inhibition dimensions - inhibition due to threat of performance failure (SIS1) and inhibition due to threat of performance consequences (SIS2). Moreover, gender, SES and SIS1 (reflecting inhibition due to threat of performance failure) were positively related to $\mathrm{CSB}$.

\section{Traumatic Experiences}

Several studies aimed to verify whether a child sexual abuse (CSA) may play a role in the development of CSB symptoms. $^{123,134-138}$ Meyer and colleagues ${ }^{134}$ examined gender differences in this area in a study on a sample of 504 women and 308 men aged 18-78 years. In addition to the result suggesting CSB (assessed by SAST-R) ${ }^{98}$ being less present among women regardless of the history of sexual abuse, authors have, however, found that participants (both men and women) with a history of CSA reported more attachment anxiety in romantic relationships than those without a history of CSA. Castellini and colleagues' study ${ }^{123}$ revealed an association between childhood adversities (assessed by The Childhood Experience of Care and Abuse) ${ }^{139}$ and CSB (assessed by Hypersexual Disorder Screening Inventory) ${ }^{128}$ among women, but not among men.

Another four studies were carried out by VaillancourtMorel and colleagues on Canadian samples. ${ }^{135-138}$ The first study involved a group of 529 women and 157 men aged 18-77 years that currently were in a close relationship, of which $20 \%$ women and $19 \%$ men with a history of CSA. ${ }^{135}$ Specifically, they found that CSA was associated with a higher level of sexual avoidance and sexual compulsivity (assessed by SCS), ${ }^{83}$ which was a predictor of lower couple adjustment. In 2016, the authors conducted the second study in order to test a mediation model assuming that the relationship between CSA severity and extradyadic sexual involvement (ESI) may be explained through sexual compulsivity. ${ }^{136}$ The study sample consisted of 521 women and 148 men (aged 18-77 years) involved in a close relationship. The results were as follows: CSA severity was positively and significantly associated with sexual compulsivity, which predicted ESI; there was a direct relationship between CSA and EDI; high CSA severity led - through a high sexual compulsivity - to the highest likelihood of ESI; CSB severity was lower among women; there was no gender difference in the structural association between CSA, ESI and sexual compulsivity. The third study was conducted on a group of 756 women and 265 men aged $18-77 .{ }^{137}$ In total sample, $21.3 \%$ of women and $19.6 \%$ of men experienced legally defined CSA, of which 54 women and 10 men defined their incident as sexual abuse (self-definers). Results reveal an association between self-defined CSA and higher 
negative post-abuse reactions and sexual avoidance, while not identifying as sexually abused was related to higher sexual compulsion. The last study by Vaillancourt-Morel and colleagues ${ }^{138}$ involved 1033 participants aged 18-77 (760 women) and found that sexual outcomes of CSA differed according to relationship status. Regardless of gender, CSA severity was related to higher sexual compulsivity in single participants, higher sexual avoidance and compulsivity in cohabiting participants, and higher sexual avoidance in those who were married.

\section{Treatment of CSB Among Women}

Three studies conducted on groups of treatment-seeking /receiving individuals were discovered. ${ }^{84,86,140}$ Seven hundred and nineteen Polish women aged 14-63 years took part in a survey study of Lewczuk and colleagues. ${ }^{140}$ Thirty-nine of women were treatment seekers for PPU. Results showed higher scores in terms of the number of symptoms related to pornography use and the amount of pornography use among treatment seekers (compared to non-treatment seeking women). Additionally, treatment seekers reported a higher maximal number of masturbations per day and longer episodes of binge pornography watching. A path analysis model showed that the amount of pornography use was significantly related to treatment-seeking, and this relationship remained positive and significant after introducing the mediator - severity of symptoms associated with pornography consumption. Interestingly, authors found a loss of significance of the positive association between the amount of pornography use and treatment-seeking when they included two other predictors to the model: religious practices (assessed by the reported average amount of time [minutes per week] spent on practices such as prayers, participation in services, reading spiritual books, and meditations) and symptoms associated with pornography use. Finally, the authors found a correlation between depression, anxiety, and PPU among women, suggesting that a higher level of PPU may be associated with a greater level of psychopathology.

Two aforementioned studies of Brem and colleagues involving individuals in residential treatment for SUDs ${ }^{84,86}$ revealed a negative association between CSB symptom severity and dispositional mindfulness (assessed by Mindful Attention Awareness Scale) ${ }^{141}$ among women with SUD, pointing to the potential utility of using mindfulness-based approaches in treating women with CSB and SUD.

\section{Discussion}

The decision on including CSBD in the forthcoming 11th edition of the International Classification of Diseases, despite the potential benefits, remains hotly debated among scientists and clinicians. ${ }^{18,142-144}$ Whether mechanisms underlying CSBD are impulsive, compulsive, or addictive remains a contentious issue. The placement of CSBD in medical classification will undoubtedly contribute to the acceleration of research focusing on the definition, classification, and theoretical framework of CSBD, which may in turn allow for the development of effective treatments for people experiencing these problems. The current conceptualization of CSBD was preceded by numerous studies involving mainly heterosexual men; thus, applying diagnostic criteria to women or sexual minorities is short-sided. Accuracy of diagnostic criteria in the evaluation of CSBD women and non-heterosexual samples should be further evaluated in large, culturally diverse samples of men and women.

One of the missing gaps in the literature pertains to the lack of scientific investigation on CSB among women and sexual minorities, ${ }^{145,146}$ focusing on prevalence estimates, clinical patterns of sexual functioning, as well as neurobiological mechanisms. According to Böthe and colleagues' review of literature on LGBTQ adolescents, ${ }^{146}$ of eleven studies published in the past 5 years, only two focused exclusively on CSB among the reviewed group. Moreover, the authors pointed to the lack of quantitative investigations concentrated on comparison to heterosexual individuals and taking into account ethnic diversities.

To our best knowledge, this is the first review aimed at summarizing the current state of knowledge about CSB among women to elucidate current gaps as well as generate areas for future research exploration. In this section, we summarize the most important research findings for consideration.

In the context of the prevalence of CSB, research indicated that fewer women (as compared to men) reported viewing pornographic materials over the last 6 months, ${ }^{44}$ they reported less pornography time use $\mathrm{u}^{44,46-48,77}$ and exhibited lower rates of feeling urges to pornography, ${ }^{45}$ a smaller percentage of them self-identified as addicted to pornography based on subjective feeling, ${ }^{14}$ and fewer women reported symptoms related to $\mathrm{CSB}$, such as difficulties in controlling sexual thoughts and behaviors, engaging in sexual activity to cope with unpleasant emotional states, and experiencing negative consequences because of 
these sexual behaviors. ${ }^{50-53,55-57,63,75,77,89,90,109,111,134,136}$ It is worth noting that prior research focused on measuring PPU and masturbation and has been conducted almost exclusively in men, and prior work has not included a deeper analysis of patterns of sexual functioning of women who reported issues related to CSB. We also note that the subjective assessment of addiction to pornography does not necessarily reflect a CSBD diagnosis in women. CSBD diagnosis should be confirmed through clinical evaluations by trained medical professionals. Another point worth mentioning is a lack of clinically validated CSB measures for women. Many of the current CSB measures were developed using the diagnosis criteria for Hypersexual Disorder (HD) proposed to DSM-5. ${ }^{28}$ The diagnostic criteria for $\mathrm{HD}$ and $\mathrm{CSB}$ do not completely overlap in several regards. It is unknown what diagnostic criteria were used in many of the reviewed studies; hence, discrepancies in prevalence statistics exist. For example, Engel and colleagues ${ }^{52}$ used only HBI-19 questionnaire to assess CSB symptoms severity; however, in their discussion, they emphasized the need for conducting clinical interviews to classify someone with CSB.

The results of studies examining CSB from the perspective of behavioral and cognitive processes remain inconsistent, which makes it difficult to draw clear conclusions from these studies. On one hand, studies of Pekal and colleagues ${ }^{75}$ and Sklenarik and colleagues ${ }^{147}$ showed that enhanced attentional bias toward pornographic stimuli among women was associated with higher severity of symptoms related to addictive usage of pornography and higher anhedonia. These results are in line with several studies on substance-use disorders ${ }^{148}$ and behavioral addictions. ${ }^{149}$ On another hand, there are studies showing lower attentional biases in women (as compared to men) as well as studies that did not show any sex differences. ${ }^{150,151}$ The authors posited that these pornographic pictures have stronger rewarding characteristics for men than women. However, most recent research on neural correlates of erotic stimuli processing showed no sex differences. ${ }^{152}$ Therefore, it is important to investigate other factors, such as a history of exposure for erotic content or recent sexual activity. For example, in Albery and colleagues' investigation, ${ }^{76}$ sexually active participants exhibited a greater tendency to preferentially process sex-related words than neutral stimuli. These results support prior findings indicating the existence of a similar pattern for substance-related ${ }^{153}$ and non-substance-related behavior. $^{2,149,150,154}$ No effect of gender on interference scores was noted. Finally, Stark and colleagues ${ }^{77}$ found only approach biases for pornography among participants having greater problems with its consumption.

Five studies revealed that CSB symptoms may comorbid with symptoms of Substance Use Disorder (SUD). ${ }^{84-88}$ Interestingly, two of them ${ }^{84,86}$ indicated a negative relationship between CSB and tendencies to be aware of the present moment, suggesting that approach based on mindfulness techniques should be further examined in the context of its potential effectiveness in working with women. A deeper examination of the co-occurrence of CSB and SUD should be considered in women. According to Carnes, ${ }^{155} \mathrm{CSB}$ and substance use are woven together (eg, substance use can lead to engaging in problematic sexual behavior or substance use may enhance sexual experience, reinforcing the pairing of these problematic behaviors). Preliminary evidence suggests that in women (similar to men) drug use may be a risk factor for CSB. ${ }^{156}$ Women's problems with substance use have been found to be positively associated with negative mood states (eg, feeling depressed, degraded) after being preoccupied with sexual thoughts, fantasies, and behaviors.

Two studies ${ }^{87,95}$ indicated a relationship between CSB and borderline personality symptoms, which has been previously well documented in the literature, ${ }^{83,157-159}$ and has been found to occur more often in women compared to men. ${ }^{160}$ Interestingly, both CSB and borderline personality are characterized by the lack of impulse control, ${ }^{158}$ which is often manifested by engaging in problematic and risky sexual behavior, such as having multiple sexual partners or unprotected sex, ${ }^{158,161-164}$ as well as preoccupation with sexual fantasies ${ }^{165}$ and distress related to sexual behavior. ${ }^{165}$ In the case of women who exhibit more borderline personality features, previous studies showed that they more likely report more sexual partners, ${ }^{83,166,167}$ more casual sexual partners, ${ }^{167}$ and earlier age of sexual initiation. ${ }^{168}$ Many factors are related to increased numbers of sexual partners in people with severe psychiatric conditions (eg, substance use, childhood sexual abuse, being unmarried). ${ }^{169}$ Association between borderline personality symptoms and the numbers of sexual partners may be explained by greater substance use. For example, among individuals with BPD, those who reported using substances also reported more sexual partners. ${ }^{163,170}$ Findings from two studies included in this review are consistent with prior studies showing a strong co-occurrence between CSB and borderline personality symptoms in both non-clinical ${ }^{95}$ and clinical samples with substance-use disorder. ${ }^{87}$ 
Further, CSB symptoms have been found to be associated with ADHD symptoms, ${ }^{92}$ obsessive-compulsive disorder, ${ }^{93}$ and pathological buying. ${ }^{90}$ Further work is needed to identify effective treatments for CSB and other co-occurring disorders among treatment-seeking women.

In the case of personality factors in females, PPU has been positively related with trait psychopathy, ${ }^{107}$ sexual sensation seeking was positively correlated with sexual compulsivity, ${ }^{108}$ but a model assuming that sexual sensation seeking may impact PPU through online sexual activities, and may be influenced by the third-person effect applied to women less so than men. ${ }^{109}$ Another examination revealed that impulsivity was stronger (but only moderately) associated with $\mathrm{CSB}^{104}$ than was compulsivity for women. Other studies found that motor/planning impulsiveness, negative affect, and psychoticism significantly predicted sexual compulsivity. ${ }^{106}$

Additionally, CSB symptom severity has been found to be associated with sexual dysfunctions, and more generally with psychopathology. ${ }^{123}$ The results of another study showed a positive correlation between sexual compulsivity and both anxious and avoidant attachment. ${ }^{125}$ Finally, one study showed an association between childhood adversities and CSB among women, ${ }^{123}$ and another four studies revealed a relationship between sexual compulsivity and child sexual abuse (CSA). ${ }^{135-138}$ Prior works have found a significant relationship between CSA and insecure attachment ${ }^{171-173}$ and demonstrated their high prevalence among individuals with CSB symptoms. CSA is being considered as an important factor in the development of CSB. ${ }^{174-178}$ Some researchers proposed that CSB symptoms occur as a form of regulatory behavior of coping with stressors related to CSA and negative emotions. ${ }^{135,179-184}$ As noted by others, ${ }^{185}$ longitudinal studies using a cohort design are needed to assess the trajectory of sexually related responses (ie, sexual avoidance, compulsivity, and ambivalence) across the lifespan for women and men reporting histories of CSA or other forms of child maltreatment.

No studies are assessing the effectiveness of treatment in women with CSB, only gender differences in predictors of treatment-seeking have been identified so far $^{38,140 .}$ For women, the mere amount of pornography use, symptoms related to its consumption, as well as religiosity were associated with treatment-seeking behavior, ${ }^{140}$ while among men symptoms of pornography use predicted treatment-seeking behavior more strongly than the quantity of consumption. ${ }^{38}$

\section{Limitations}

Little scientific attention devoted to the issue of CSB in women resulting in a paucity of accurate estimates of the prevalence and the problem in this group. Moreover, prior studies mostly included measurement of characteristics and CSB behavior in general populations (non-clinical), with a lack of research carried out on the population of women diagnosed with CSBD. A study on the prevalence of CSB among patients with Parkinson's disease ${ }^{94}$ did not provide information on whether the effects of L-Dopa and dopamine agonists that may cause CSB were considered. Given the absence of clinically relevant research on women with CSB, the current state of the data does not provide adequate treatment guidelines for women suffering from this condition. Due to these limitations, we cannot draw conclusions regarding best clinical practices for medical providers working with women reporting issues with CSB.

An additional point worth emphasizing is that many of the reviewed studies were conducted on Western, educated, industrialized, rich, and democratic (WEIRD) societies. ${ }^{186}$ As participants from these societies (predominantly college students) represent approximately $80 \%$ of all study participants, they are unrepresentative of most people living with CSB. Results from studies using WEIRD samples do not generalize well for clinical populations or those from nonWestern societies or individuals from culturally diverse backgrounds. We hope that generalization drawn from our review will help inform the next steps for CSB research in women, but do caution the reader about making strong conclusions from our systematic review.

\section{Future Directions}

Our first recommendation is for future investigations to concentrate on obtaining accurate epidemiological data on women with CSB. The aforementioned prevalence estimates are derived from research involving mostly heterosexual men, which limits generalizability for women. There is also a need for conducting studies in clinical samples of women in order to identify patterns of their sexual functioning, the occurrence of sexual dysfunctions, possible cooccurrence of CSB with other impulse control disorders, addictive or mental health disorders, and specific personality profiles. Since we do not have a clinical picture of women experiencing CSB, it is recommended that future research assess the psychological role of certain behaviors, and its impact on various aspects, including relationships, sexual and psychosocial functioning. Such data would allow for 
Table I Recommendations for Future Studies of Compulsive Sexual Behavior Disorder Among Women

\begin{tabular}{|c|c|}
\hline Data & Goal \\
\hline $\begin{array}{l}\text { Clinical } \\
\text { Self-report }\end{array}$ & - Conduct large epidemiological studies \\
\hline $\begin{array}{l}\text { Clinical } \\
\text { Behavioral } \\
\text { Self-report } \\
\text { Neurobiological }\end{array}$ & $\begin{array}{l}\text { - Assess and validate proposed CSBD diagnostic criteria in the context of women in clinical settings } \\
\text { - Identify (dominant) patterns of sexual functioning of CSBD women } \\
\text { - Examine the occurrence of sexual dysfunctions among women with CSBD } \\
\text { - Examine possible co-occurrence of CSB with other impulse control disorders, addictive/mental health disorders and } \\
\text { specific personality profiles } \\
\text { - Identify the clinical picture of women with CSBD (eg, psychological role of certain behaviors, its impact on relationships } \\
\text { and sexual and psychosocial functioning) } \\
\text { - Examine the role of impulsivity/compulsivity in the development and maintenance of CSBD } \\
\text { - Examine the relationship between neuronal mechanisms and treatment outcomes for treatment-seeking women with } \\
\text { CSBD }\end{array}$ \\
\hline $\begin{array}{l}\text { Clinical } \\
\text { Pharmacological } \\
\text { Neurobiological }\end{array}$ & - Conduct randomized clinical trials to identify efficacious pharmacological and behavioral treatments/interventions \\
\hline Neurobiological & $\begin{array}{l}\text { - Investigate structural, functional, neurochemical and other data and their integration } \\
\text { - Verify potential differences in neuronal mechanisms of CSBD between women and men } \\
\text { - Examine neurobiological mechanisms underlying specific aspects of CSBD }\end{array}$ \\
\hline Genetic & $\begin{array}{l}\text { - Conduct genome-wide association studies (GWAS) on women with CSBD } \\
\text { - Examine vulnerability genetic factors for the development and maintenance of CSBD } \\
\text { - Examine environmental and epigenetic influences on processes in CSBD }\end{array}$ \\
\hline
\end{tabular}

Note: Compulsive sexual behavior disorder (CSBD).

developing culturally appropriate CSB treatment for women with diverse life experiences. Furthermore, it is important to verify the potential difference in neuronal mechanisms underlying CSB between women and men, as well as examine genetic vulnerability factors for the development and maintenance of CSBD in this group. Future research should also concentrate on testing therapeutic interventions for women reporting issues with CSB, albeit in its various forms (ie, repetitive pornography use, masturbation, casual and risky sexual encounters, etc.). Our recommendation for future studies with women reporting issues with CSBD are presented in Table 1.

\section{Conclusions}

To summarize the reviewed literature, available studies indicate that CSB symptom severity is lower in women than in men. The following indicators have been examined in terms of their relationships with CSB symptoms among women and men: attentional bias toward sex-related stimuli, substance use and problems, depression symptoms, early maladaptive schemas, compulsive/pathological buying, ADHD symptoms, obsessive-compulsive disorder, Impulsive-
Compulsive Disorders, Autism Spectrum Disorder, trait impulsiveness, compulsiveness and motivation, "the dark triad of personality", sexual sensation seeking, gender identity, sexual dysfunctions, "third-person effect", general psychopathology, sexual satisfaction, sexting behaviors, difficulties in intimacy, insecure attachments, sexual excitation and sexual inhibition, child sexual abuse, dispositional mindfulness, and treatment-seeking behavior. Studies assessing the relationship between CSB and borderline personality features, sexual aggression, and negative affect-have been conducted on female samples only, therefore, it is difficult to establish a gender-specific relationship. Overall, the results of the research described in this paper do not provide a clear understanding of the patterns of sexual functioning in women with CSB. Further research is needed to address gaps in understanding about possible gender differences in the clinical manifestation of CSB in women and men.

\section{Human and Animal Rights and Informed Consent}

This article does not contain any studies with human or animal subjects performed by any of the authors. 


\section{Disclosure}

Prof. Dr. Michal Lew-Starowicz reports grants from European Society for Sexual Medicine, non-financial support from Lundbeck, outside the submitted work; and received honoraria for lectures from Angelini SpA, Aurovitas-Apotex, MCO International SRL, Mylan Healthcare, Lundbeck, Sanofi and Servier. He also receives advisory board honoraria from Novo Nordisk. Travel/meeting expenses and writing support received from CREMS SLR. These activities were not related to the research or clinical activity related to the topic of the manuscript. In the preparation of this manuscript, Ewelina Kowalewska and Michal Lew-Starowicz were financially supported by the Centre of Medical Postgraduate Education (statutory funding, the program no 501-1-065-38-19), and Ewelina Kowalewska was supported by Polish National Science Centre, PRELUDIUM grant number 2017/27/N/HS6/02079. Mateusz Gola was supported by the Polish National Agency for Academic Exchange grant PPN/BEK/2019/ $1 / 00245$. The authors declare that they have no other conflicts of interest.

\section{References}

1. Kraus SW, Voon V, Potenza MN. Should compulsive sexual behavior be considered an addiction? Addiction. 2016;111(12):2097-2106. doi:10.1111/add.13297

2. Voon V, Mole TB, Banca P, et al. Neural correlates of sexual cue reactivity in individuals with and without compulsive sexual behaviours. PLoS One. 2014;9(7):e102419. doi:10.1371/journal. pone. 0102419

3. Klucken T, Wehrum-Osinsky S, Schweckendiek J, Kruse O, Stark R. Altered appetitive conditioning and neural connectivity in subjects with compulsive sexual behavior. J Sex Med. 2016;13(4):627-636. doi:10.1016/j.jsxm.2016.01.013

4. Brand M, Snagowski J, Laier C, Maderwald S. Ventral striatum activity when watching preferred pornographic pictures is correlated with symptoms of internet pornography addiction. NeuroImage. 2016;129:224-232. doi:10.1016/j.neuroimage.2016.01.033

5. Gola M, Wordecha M, Sescousse G, et al. Can pornography be addictive? An fMRI study of men seeking treatment for problematic pornography use. Neuropsychopharmacology. 2017;42(10):2021-2031. doi:10.1038/ npp. 2017.78

6. Seok JW, Sohn JH. Gray matter deficits and altered resting-state connectivity in the superior temporal gyrus among individuals with problematic hypersexual behavior. Brain Res. 2018;1684:30-39. doi:10.1016/j.brainres.2018.01.035

7. Sinke C, Engel J, Veit M, et al. Sexual cues alter working memory performance and brain processing in men with compulsive sexual behavior. NeuroImage Clin. 2020;27:102308. doi:10.1016/j. nicl.2020.102308

8. Draps M, Sescousse G, Potenza MN, et al. Gray matter volume differences in impulse control and addictive disorders - an evidence from a sample of heterosexual males. $J$ Sex Med. 2020. doi:10.1016/j. jsxm.2020.05.007
9. Seok JW, Sohn JH. Response inhibition during processing of sexual stimuli in males with problematic hypersexual behavior. J Behav Addict. 2020;9(1):71-82. doi:10.1556/2006.2020.00003

10. Gola M, Potenza MN. Paroxetine treatment of problematic pornography use: a case series. $J$ Behav Addict. 2016;5(3):529-532. doi:10.1556/2006.5.2016.046

11. Efrati Y, Gola M. Treating compulsive sexual behavior. Curr Sex Health Rep. 2018;10(2):57-64. doi:10.1007/s11930-018-0143-8

12. Blycker GR, Potenza MN. A mindful model of sexual health: a review and implications of the model for the treatment of individuals with compulsive sexual behavior disorder. $J$ Behav Addict. 2018;7(4):917-929. doi:10.1556/2006.7.2018.127

13. Kraus SW, Meshberg-Cohen S, Martino S, Quinones LJ, Potenza MN. Treatment of compulsive pornography use with naltrexone: a case report. Am $J$ Psychiatry. 2015;172 (12):1260-1261. doi:10.1176/appi.ajp.2015.15060843

14. Grubbs JB, Kraus SW, Perry SL. Self-reported addiction to pornography in a nationally representative sample: the roles of use habits, religiousness, and moral incongruence. $J$ Behav Addict. 2019;8(1):88-93. doi:10.1556/2006.7.2018.134

15. Kraus SW, Krueger RB, Briken P, et al. Compulsive sexual behaviour disorder in the ICD-11. World Psychiatry. 2018;17 (1):109-110. doi:10.1002/wps.20499

16. Lew-Starowicz M, Lewczuk K, Nowakowska I, Kraus SW, Gola M. Compulsive sexual behavior and dysregulation of emotion. Sex Med Rev. 2020;8(2):191-205. doi:10.1016/j. sxmr.2019.10.003

17. Kraus SW, Sweeney PJ. Hitting the target: considerations for differential diagnosis when treating individuals for problematic use of pornography. Arch Sex Behav. 2019;48(2):431-435. doi:10.1007/s10508-018-1301-9

18. Gola M, Potenza MN. Promoting educational, classification, treatment, and policy initiatives: commentary on: compulsive sexual behaviour disorder in the ICD-11 (Kraus et al., 2018). J Behav Addict. 2018;7(2):208-210. doi:10.1556/2006.7.2018.51

19. World Health Organization (WHO). ICD-11. version 04/2019. Compulsive sexual behavior disorder. Geneva: WHO; 2019. Available from: https://icd.who.int/browse11/l-m/en\#/http\%3a\%2f\% 2fid.who.int $\% 2$ ficd $\% 2$ fentity $\% 2$ f1630268048. Accessed March 25, 2020.

20. Chivers ML. Leading comment: a brief review and discussion of sex differences in the specificity of sexual arousal. Sex Relation Ther. 2005;4(4):377-390. doi:10.1080/14681990500238802

21. Chivers ML, Bailey JM. A sex difference in features that elicit genital response. Biol Psychol. 2005;70(2):115-120. doi:10.1016/ j.biopsycho.2004.12.002

22. Murnen SK, Stockton M. Gender and self-reported sexual arousal in response to sexual stimuli: a meta-analytic review. Sex Roles. 1997;37(3/4):135-153. doi:10.1023/A:1025639609402

23. Wood JR, McKay A, Komarnicky T, Milkausen RR. Was it good for you too? An analysis of gender differences in oral sex practices and pleasure ratings among heterosexual Canadian university students. Can J Hum Sex. 2016;25(1):21-29. doi:10.3138/ cjhs.251-A2

24. Hsu B, Kling A, Kessler C, Knapke K, Diefenbach P, Elias JE. Gender differences in sexual fantasy and behavior in a college population: a ten-year replication. J Sex Marital Ther. 1994;20 (2):103-118. doi:10.1080/00926239408403421

25. Masters WH, Johnson VE. Human Sexual Response. Toronto, New York: Bantam Books; 1966.

26. Basson R. The female sexual response: a different model. $J$ Sex Marital Ther. 2000;26(1):51-65. doi:10.1080/009262300278641

27. Basson R. Women's sexual dysfunction: revised and expanded definitions. CMAJ. 2005;172(10):1327-1333. doi:10.1503/ cmaj. 1020174 
28. Kafka MP. Hypersexual disorder: a proposed diagnosis for DSM-V. Arch Sex Behav. 2010;39(2):377-400. doi:10.1007/ s10508-009-9574-7

29. Kaplan MS, Krueger RB. Diagnosis, assessment, and treatment of hypersexuality. J Sex Res. 2010;47(2):181-198. doi:10.1080/ 00224491003592863

30. Reid RC. Personal perspectives on hypersexual disorder. Sex Addict Compulsivity. 2013;20:4-18.

31. Black DW. The epidemiology and phenomenology of compulsive sexual behavior. CNS Spectr. 2000;5(1):26-72. doi:10.1017/ S1092852900012645

32. Carnes P. Don't Call It Love. Recovery from Sexual Addiction. New York: Bantam; 1991.

33. Coleman E. Is your patient suffering from compulsive sexual behavior? Psychiatr Ann. 1992;22(6):320-325. doi:10.3928/ 0048-5713-19920601-09

34. Kuzma JM, Black DW. Epidemiology, prevalence, and natural history of compulsive sexual behavior. Psychiatr Clin $\mathrm{N} \mathrm{Am}$. 2008;31(4):603-611. doi:10.1016/j.psc.2008.06.005

35. Prause N. Evaluate models of high-frequency sexual behaviors already. Arch Sex Behav. 2017;46(8):2269-2274. doi:10.1007/ s10508-017-1078-2

36. Reid RC, Carpenter BN, Hook JN, et al. Report of findings in a DSM-5 field trial for hypersexual disorder. J Sex Med. 2012;9 (11):2868-2877. doi:10.1111/j.1743-6109.2012.02936.x

37. Lewczuk K, Glica A, Nowakowska I, Gola M, Grubbs JB. Evaluating pornography problems due to moral incongruence model. J Sex Med. 2020;17(2):300-311. doi:10.1016/j. jsxm.2019.11.259

38. Gola M, Lewczuk K, Skorko M. What matters: quantity or quality of pornography use? Psychological and behavioral factors of seeking treatment for problematic pornography use. J Sex Med. 2016;13(5):815-824. doi:10.1016/j.jsxm.2016.02.169

39. Stein DJ, Black DW, Shapira NA, Spitzer RL. Hypersexual disorder and preoccupation with internet pornography. $\mathrm{Am}$ $J \quad$ Psychiatry. 2001;158(10):1590-1594. doi:10.1176/appi. ajp.158.10.1590

40. Moher D, Liberati A, Tetzlaff J, Altman DG. PRISMA group. Preferred reporting items for systematic reviews and meta-analyses: the PRISMA statement. PLoS Med. 2009;6(7): e1000097. doi:10.1371/journal.pmed.1000097

41. Baranowski AM, Vogl R, Stark R. Prevalence and determinants of problematic online pornography use in a sample of german women. J Sex Med. 2019;16(8):1274-1282. doi:10.1016/j. jsxm.2019.05.010

42. Rissel C, Richters J, de Visser RO, McKee A, Yeung A, Caruana T. A profile of pornography users in Australia: findings from the second Australian study of health and relationships. J Sex Res. 2017;54(2):227-240. doi:10.1080/ 00224499.2016 .1191597

43. Daspe MÈ, Vaillancourt-Morel MP, Lussier Y, Sabourin S, Ferron A. When pornography use feels out of control: the moderation effect of relationship and sexual satisfaction. $J$ Sex Marital Ther. 2018;44(4):343-353. doi:10.1080/ 0092623X.2017.1405301

44. Blais-Lecours S, Vaillancourt-Morel MP, Sabourin S, Godbout N. Cyberpornography: time use, perceived addiction, sexual functioning, and sexual satisfaction. Cyberpsychol Behav Soc Netw. 2016;19(11):649-655. doi:10.1089/cyber.2016.0364

45. Weinstein AM, Zolek R, Babkin A, Cohen K, Lejoyeux M. Factors predicting cybersex use and difficulties in forming intimate relationships among male and female users of cybersex. Front Psychiatry. 2015;6:e54. doi:10.3389/fpsyt.2015.00054

46. Harper C, Hodgins DC. Examining correlates of problematic internet pornography use among university students. J Behav Addict. 2016;5(2):179-191. doi:10.1556/2006.5.2016.022
47. Vaillancourt-Morel MP, Blais-Lecours S, Labadie C, Bergeron S, Sabourin S, Godbout N. Profiles of cyberpornography use and sexual well-being in adults. $J$ Sex Med. 2017;14(1):78-85. doi:10.1016/j.jsxm.2016.10.016

48. Ballester-Arnal R, Castro-Calvo J, Gil-Llario MD, Gil-Julia B. Cybersex addiction: a study on spanish college students. J Sex Marital Ther. 2017;43(6):567-585. doi:10.1080/ 0092623X.2016.1208700

49. Dickenson JA, Gleason N, Coleman E, Miner MH. Prevalence of distress associated with difficulty controlling sexual urges, feelings, and behaviors in the United States. JAMA Netw Open. 2018;1(7):e184468. doi:10.1001/jamanetworkopen.2018.4468

50. Walton MT, Cantor JM, Lykins AD. An online assessment of personality, psychological, and sexuality trait variables associated with self-reported hypersexual behavior. Arch Sex Behav. 2017;46 (3):721-733. doi:10.1007/s10508-015-0606-1

51. Kraus SW, Martino S, Potenza MN, Park C, Merrel JD, Hoff RA. Examining compulsive sexual behavior and psychopathology among a sample of postdeployment U.S. male and female military veterans. Mil Psychol. 2017;29(2):143-156. doi:10.1037/ mil0000147

52. Engel J, Kessler A, Veit M, et al. Hypersexual behavior in a large online sample: individual characteristics and signs of coercive sexual behavior. $J$ Behav Addict. 2019;8(2):213-222. doi:10.1556/2006.8.2019.16

53. Bőthe B, Bartók R, Tóth-Király I, et al. Hypersexuality, gender, and sexual orientation: a large-scale psychometric survey study. Arch Sex Behav. 2018;47(8):2265-2276. doi:10.1007/s10508018-1201-z

54. Tripodi F, Eleuteri S, Giuliani M, et al. Unusual online sexual interests in heterosexual Swedish and Italian university students. Sexologies. 2015;24(4):e84-e93. doi:10.1016/j.sexol.2015.03.003

55. Mulhauser K, Miller Short E, Weinstock J. Development and psychometric evaluation of the pornography purchase task. Addict Behav. 2018;84:207-214. doi:10.1016/j.addbeh.2018.04.016

56. Zilberman N, Yadid G, Efrati Y, Neumark Y, Rassovsky Y. Personality profiles of substance and behavioral addictions. Addict Behav. 2018;82:174-181. doi:10.1016/j.addbeh.2018.03.007

57. Efrati Y. Adolescent compulsive sexual behavior: is it a unique psychological phenomenon? J Sex Marital Ther. 2018;44 (7):687-700. doi:10.1080/0092623X.2018.1452088

58. Werner M, Štulhofer A, Waldorp L, Jurin T. A network approach to hypersexuality: insights and clinical implications. J Sex Med. 2018;15(3):373-386. doi:10.1016/j.jsxm.2018.01.009

59. Graham FJ, Walters GD, Harris DA, Knight RA. Is hypersexuality dimensional or categorical? Evidence from male and female college samples. J Sex Res. 2016;53(2):224-238. doi:10.1080/ 00224499.2014.1003524

60. Kingston DA, Walters GD, Olver ME, Levaque E, Sawatsky M, Lalumière ML. Understanding the latent structure of hypersexuality: a taxometric investigation. Arch Sex Behav. 2018;47 (8):2207-2221. doi:10.1007/s10508-018-1273-9

61. Carvalho J, Stulhofer A, Vieira AL, Jurin T. Hypersexuality and high sexual desire: exploring the structure of problematic sexuality. J Sex Med. 2015;12(6):1356-1367. doi:10.1111/ jsm. 12865

62. Štulhofer A, Bergeron S, Jurin T. Is high sexual desire a risk for women's relationship and sexual well-being? J Sex Res. 2016;53 (7):882-891. doi:10.1080/00224499.2015.1084984

63. Efrati Y, Gola M. Understanding and predicting profiles of compulsive sexual behavior among adolescents. J Behav Addict. 2018;7(4):1004-1014. doi:10.1556/2006.7.2018.100

64. Grubbs JB, Volk F, Exline JJ, Pargament KI. Internet pornography use: perceived addiction, psychological distress, and the validation of a brief measure. J Sex Marital Ther. 2015;41(1):83-106. doi:10.1080/0092623X.2013.842192 
65. Petry NM, Rehbein F, Gentile DA, et al. An international consensus for assessing internet gaming disorder using the new DSM-5 approach. Addiction. 2014;109(9):1399-1406. doi:10.1111/add.12457

66. Cooper A, Delmonico DL, Burg R. Cybersex users, abusers, and compulsives: new findings and implications. Sex Addict Compulsivity. 2000;7(1-2):5-29. doi:10.1080/10720160008400205

67. Miner MH, Raymond N, Coleman E, Swinburne Romine R. Investigating clinically and scientifically useful cut points on the compulsive sexual behavior inventory. J Sex Med. 2017;14 (5):715-720. doi:10.1016/j.jsxm.2017.03.255

68. Reid RC, Garos S, Carpenter BN. Reliability, validity, and psychometric development of the hypersexual behavior inventory in an outpatient sample of men. Sex Addict Compulsivity. 2011;18 (1):30-51. doi:10.1080/10720162.2011.555709

69. Kroenke K, Spitzer RL. The PHQ-9: a new depression diagnostic and severity measure. Psychiatr Ann. 2002;32(9):509-515. doi:10.3928/0048-5713-20020901-06

70. Delmonico DL, Miller JA. The internet sex screening test: a comparison of sexual compulsives versus non-sexual compulsives. Sex Relatsh Ther. 2003;18(3):261-276. doi:10.1080/1468199031000153900

71. Reid RC, Li DS, Gilliland R, Stein JA, Fong T. Reliability, validity, and psychometric development of the pornography consumption inventory in a sample of hypersexual men. $J$ Sex Marital Ther. 2011;37(5):359-385. doi:10.1080/ 0092623X.2011.607047

72. Kor A, Zilcha-Mano S, Fogel YA, Mikulincer M, Reid RC, Potenza MN. Psychometric development of the problematic pornography use scale. Addict Behav. 2014;39(5):1-8. doi:10.1016/j. addbeh.2014.01.027

73. Efrati Y, Mikulincer M. Individual-based compulsive sexual behavior scale: its development and importance in examining compulsive sexual behavior. J Sex Marital Ther. 2018;44 (3):249-259. doi:10.1080/0092623X.2017.1405297

74. Borsboom D, Cramer AO. Network analysis: an integrative approach to the structure of psychopathology. Annu Rev Clin Psychol. 2013;9(1):91-121. doi:10.1146/annurev-clinpsy -050212-185608

75. Pekal J, Laier C, Snagowski J, Stark R, Brand M. Tendencies toward Internet-pornography-use disorder: differences in men and women regarding attentional biases to pornographic stimuli. J Behav Addict. 2018;7(3):574-583. doi:10.1556/ 2006.7.2018.70

76. Albery IP, Lowry J, Frings D, Johnson HL, Hogan C, Moss AC. Exploring the relationship between sexual compulsivity and attentional bias to sex-related words in a cohort of sexually active individuals. Eur Addict Res. 2017;23(1):1-6. doi:10.1159/ 000448732

77. Stark R, Kruse O, Snagowski J, et al. Predictors for (problematic) use of Internet sexually explicit material: role of trait sexual motivation and implicit approach tendencies towards sexually explicit material. Sex Addict Compulsivity. 2017;24(3):180-202. doi:10.1080/10720162.2017.1329042

78. Field M, Cox WM. Attentional bias in addictive behaviors: a review of its development, causes, and consequences. Drug Alcohol Depend. 2008;97(1-2):1-20. doi:10.1016/j. drugalcdep.2008.03.030

79. Sher KJ, Wiers RW, Field M, Stacy AW. Passion's Slave? Conscious and Unconscious Cognitive Processes in Alcohol and Drug Abuse. Oxford Handbook of Substance Use Disorders. Oxford: Oxford University Press; 2014.

80. Robinson TE, Berridge KC. The neural basis of drug craving: an incentive-sensitization theory of addiction. Brain Res Rev. 1993;18(3):247-291. doi:10.1016/0165-0173(93)90013-P
81. Pawlikowski M, Altstötter-Gleich C, Brand M. Validation and psychometric properties of a short version of young's internet addiction test. Comput Hum Behav. 2013;29(3):1212-1223. doi:10.1016/j.chb.2012.10.014

82. Bradley BP, Field M, Healy H, Mogg K. Do the affective properties of smoking-related cues influence attentional and approach biases in cigarette smokers? J Psychopharmacol. 2008;22 (7):737-745. doi:10.1177/0269881107083844

83. Kalichman SC, Rompa D. The sexual compulsivity scale: further development and use with HIV-positive persons. J Pers Assess. 2001;76(3):379-395. doi:10.1207/S15327752JPA7603_02

84. Brem MJ, Shorey RC, Anderson S, Stuart GL. Dispositional mindfulness and compulsive sexual behavior among women in residential treatment for substance use disorders. Mindfulness. 2018;9(1):98-104. doi:10.1007/s12671-017-0748-4

85. Brem MJ, Shorey RC, Anderson S, Stuart GL. Does experiential avoidance explain the relationships between shame, PTSD symptoms, and compulsive sexual behaviour among women in substance use treatment? Clin Psychol Psychother. 2018;25 (5):692-700. doi:10.1002/cpp.2300

86. Brem MJ, Shorey RC, Anderson S, Stuart GL. Exploring gender differences in the relationship between dispositional mindfulness and compulsive sexual behavior among adults in residential substance use treatment. Mindfulness. 2019;10(8):1592-1602. doi:10.1007/s12671-019-01117-7

87. Elmquist J, Shorey RC, Anderson S, Stuart GL. Are borderline personality symptoms associated with compulsive sexual behaviors among women in treatment for substance use disorders? An exploratory study. J Clin Psychol. 2016;72(10):1077-1087. doi: $10.1002 /$ jclp. 22310

88. Elmquist J, Shorey RC, Anderson S, Stuart GL. A preliminary investigation of the relationship between early maladaptive schemas and compulsive sexual behaviors in a substance-dependent population. J Subst Use. 2016;21(4):349-354. doi:10.3109/ 14659891.2015.1029021

89. de Mattos CN, Kim HS, Requião MG, et al. Gender differences in compulsive buying disorder: assessment of demographic and psychiatric co-morbidities. PLoS One. 2016;11(12):e0167365. doi:10.1371/journal.pone.0167365

90. Müller A, Loeber S, Söchtig J, Te Wildt B, De Zwaan M. Risk for exercise dependence, eating disorder pathology, alcohol use disorder and addictive behaviors among clients of fitness centers. J Behav Addict. 2015;4(4):273-280. doi:10.1556/ 2006.4.2015.044

91. Granero R, Fernández-Aranda F, Mestre-Bach G, et al. Compulsive buying behavior: clinical comparison with other behavioral addictions. Front Psychol. 2016;7:e914. doi:10.3389/ fpsyg.2016.00914

92. Böthe B, Koós M, Tóth-Király I, Orosz G, Demetrovics Z. Investigating the associations of adult ADHD symptoms, hypersexuality, and problematic pornography use among men and women on a largescale, non-clinical sample. J Sex Med. 2019;16(4):489-499. doi:10.1016/j.jsxm.2019.01.312

93. Fuss J, Briken P, Stein DJ, Lochner C. Compulsive sexual behavior disorder in obsessive-compulsive disorder: prevalence and associated comorbidity. J Behav Addict. 2019;8(2):242-248. doi:10.1556/2006.8.2019.23

94. El Otmani H, Mouni FZ, Abdulhakeem Z, et al. Impulse control disorders in parkinson disease: a cross-sectional study in Morocco. Rev Neurol (Paris). 2019;175(4):233-237. doi:10.1016/j.neurol.2018.07.009

95. Jardin C, Sharp C, Garey L, et al. Compelled to risk: does sexual compulsivity explain the connection between borderline personality disorder features and number of sexual partners? J Pers Disord. 2017;31(6):738-752. doi:10.1521/pedi_2017_31_277 
96. Schöttle D, Briken P, Tüscher O, Turner D. Sexuality in autism: hypersexual and paraphilic behavior in women and men with high-functioning autism spectrum disorder. Dialogues Clin Neurosci. 2017;19(4):381-393.

97. Woods H, Proeve M. Relationships of mindfulness, selfcompassion, and meditation experience with shame-proneness. $J$ Cogn Psychother. 2014;28(1):20-33. doi:10.1891/0889-8391.28.1.20

98. Carnes P, Green B, Carnes S. The same yet different: refocusing the sexual addiction screening test (SAST) to reflect orientation and gender. Sex Addict Compulsivity. 2010;17(1):7-30. doi:10.1080/10720161003604087

99. Hayes SC, Wilson KG, Gifford EV, Follette VM, Strosahl K. Experiential avoidance and behavioral disorders: a functional dimensional approach to diagnosis and treatment. J Consult Clin Psychol. 1996;64:1152-1168. doi:10.1037/0022-006X.64.6.1152

100. Young JE, Brown G. Young Schema Questionnaire. New York: Cognitive Therapy Center of New York; 2003.

101. Faber RJ, O'Guinn TC. A clinical screener for compulsive buying. J Consum Res. 1992;19(3):459-469. doi:10.1086/209315

102. Weintraub D, Mamikonyan E, Papay K, Shea JA, Xie SX, Siderowf A. Questionnaire for impulsive-compulsive disorders in Parkinson's disease-rating scale. Mov Disord. 2012;27 (2):242-247. doi:10.1002/mds.24023

103. Shimoni L, Dayan M, Cohen K, Weinstein A. The contribution of personality factors and gender to ratings of sex addiction among men and women who use the internet for sex purpose. J Behav Addict. 2018;7(4):1015-1021. doi:10.1556/2006.7.2018.101

104. Böthe B, Tóth-Király I, Potenza MN, Griffiths MD, Orosz G, Demetrovics Z. Revisiting the role of impulsivity and compulsivity in problematic sexual behaviors. J Sex Res. 2019;56 (2):166-179. doi:10.1080/00224499.2018.1480744

105. Rømer Thomsen K, Callesen MB, Hesse M, et al. Impulsivity traits and addiction-related behaviors in youth. J Behav Addict. 2018;7(2):317-330. doi:10.1556/2006.7.2018.22

106. Carvalho J, Guerra L, Neves S, Nobre PJ. Psychopathological predictors characterizing sexual compulsivity in a nonclinical sample of women. J Sex Marital Ther. 2015;41(5):467-480. doi:10.1080/0092623X.2014.920755

107. Sindermann C, Sariyska R, Lachmann B, Brand M, Montag C. Associations between the dark triad of personality and unspecified/specific forms of Internet-use disorder. $J$ Behav Addict. 2018;7(4):985-992. doi:10.1556/2006.7.2018.114

108. Burri A. Sexual sensation seeking, sexual compulsivity, and gender identity and its relationship with sexual functioning in a population sample of men and women. J Sex Med. 2017;14 (1):69-77. doi:10.1016/j.jsxm.2016.10.013

109. Chen L, Yang Y, Su W, Zheng L, Ding C, Potenza MN. The relationship between sexual sensation seeking and problematic Internet pornography use: a moderated mediation model examining roles of online sexual activities and the third-person effect. J Behav Addict. 2018;7(3):565-573. doi:10.1556/2006.7.2018.77

110. Carvalho J, Nobre PJ. Psychosexual characteristics of women reporting sexual aggression against men. J Interpers Violence. 2016;31(15):2539-2555. doi:10.1177/0886260515579504

111. Carnes P, O’Hara S. Sexual addiction screening test (SAST). Tenn Nurse. 1991;54(3):29.

112. McCrae RR, John OP. An introduction to the five-factor model and its applications. J Pers. 1992;60(2):175-215. doi:10.1111/ j.1467-6494.1992.tb00970.x

113. Lynam DR, Smith GT, Whiteside SP, Cyders MA. The UPPSP: Assessing Five Personality Pathways to Impulsive Behavior (Technical Report). West Lafayette, IN: Purdue University; 2006

114. Kraus S, Rosenberg H. The pornography craving questionnaire: psychometric properties. Arch Sex Behav. 2014;43(3):451-462. doi:10.1007/s10508-013-0229-3
115. Patton JH, Stanford MS, Barratt ES. Factor structure of the barratt impulsiveness scale. J Clin Psychol. 1995;51 (6):768-774. doi:10.1002/1097-4679(199511)51:6<768::AIDJCLP2270510607>3.0.CO;2-1

116. Watson D, Clark L, Tellegen A. Development and validation of brief measures of positive and negative affect: the PANAS scales. J Pers Soc Psychol. 1988;54(6):1063-1070. doi:10.1037/00223514.54.6.1063

117. Derogatis LR, Spencer PM. The Brief Symptom Inventory (BSI): Administration, Scoring and Procedures Manual-I. Baltimore, MD: Clinical Psychometric Research; 1982.

118. Jones DN, Paulhus DL. The role of impulsivity in the dark triad of personality. Pers Individ Differ. 2011;51(5):679-682. doi:10.1016/j.paid.2011.04.011

119. Kalichman SC, Rompa D. Sexual sensation seeking and sexual compulsivity scales: reliability, validity, and predicting HIV risk behaviors. J Pers Assess. 1995;6(3):586-602. doi:10.1207/ s15327752jpa6503_16

120. Zuckerman M, Kolin E, Price L, Zoob I. Development of a sensation-seeking scale. J Consult Psychol. 1964;28(6):477-482. doi:10.1037/h0040995

121. Rosen R, Brown C, Heiman J, et al. The Female Sexual Function Index (FSFI): a multidimensional self-report instrument for the assessment of female sexual function. $J$ Sex Marital Ther. 2000;26(2):191-208. doi:10.1080/009262300278597

122. Davison WP. The third-person effect in communication. Public Opin Q. 1983;47(1):1-15. doi:10.1086/268763

123. Castellini G, Rellini AH, Appignanesi C, et al. Deviance or normalcy? The relationship among paraphilic thoughts and behaviors, hypersexuality, and psychopathology in a sample of university students. J Sex Med. 2018;15(9):1322-1335. doi:10.1016/ j.jsxm.2018.07.015

124. Morelli M, Bianchi D, Baiocco R, Pezzuti L, Chirumbolo A. Sexting behaviors and cyber pornography addiction among adolescents: the moderating role of alcohol consumption. Sex Res Social Policy. 2017;14(2):113-121. doi:10.1007/s13178-016-0234-0

125. Weinstein A, Katz L, Eberhardt H, Cohen K, Lejoyeux M. Sexual compulsion - relationship with sex, attachment and sexual orientation. J Behav Addict. 2015;4(1):22-26. doi:10.1556/JBA.4.2015.1.6

126. Rettenberger M, Klein V, Briken P. The relationship between hypersexual behavior, sexual excitation, sexual inhibition, and personality traits. Arch Sex Behav. 2016;45(1):219-233. doi:10.1007/s10508-014-0399-7

127. Derogatis LR. SCL-90-R, Administration, Scoring, and Procedures Manual. 3rd ed. Minneapolis, MN: National Computer Systems; 1994.

128. American Psychiatric Association. Hypersexual disorder screening inventory. American psychiatric association's DSM-5 workgroup on sexual and gender identity disorders. Available from http://www.dsm5.org/ProposedRevisions/Pages/proposedrevision.

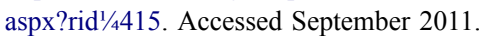

129. Morelli M, Bianchi D, Baiocco R, Pezzuti L, Chirumbolo A. Sexting, psychological distress and dating violence among adolescents and young adults. Psicothema. 2016;28(2):137-142. doi:10.7334/psicothema2015.193

130. Marenco A. Intimacy Questionnaire: SOC SOC 103. College of the Canyons: Class Note; 2014.

131. Young K. Are You Addicted to Cybersex? Bradford, PA: Center for Internet Addiction Recovery; 2001.

132. Kraus SW. Excessive appetite for pornography: development and evaluation of the pornography craving questionnaire (pcq-12). Ph.d. thesis, advisor: Rosenberg H. Bowling Green State University; 2013. Available from: http://www.researchgate.net/ publication/256096657_Excessive_Appetite_for_Pornography_ Development_and_Evaluation_of_the_Pornography_Craving Questionnaire_(PCQ-12). 
133. Janssen E, Vorst H, Finn P, Bancroft J. The sexual inhibition (SIS) and sexual excitation (SES) scales: I. measuring sexual inhibition and excitation proneness in men. J Sex Res. 2002;39(2):114-126. doi:10.1080/00224490209552130

134. Meyer D, Cohn A, Robinson B, Muse F, Hughes R. Persistent complications of child sexual abuse: sexually compulsive behaviors, attachment, and emotions. J Child Sex Abus. 2017;26 (2):140-157. doi:10.1080/10538712.2016.1269144

135. Vaillancourt-Morel MP, Godbout N, Labadie C, Runtz M, Lussier Y, Sabourin S. Avoidant and compulsive sexual behaviors in male and female survivors of childhood sexual abuse. Child Abuse Negl. 2015;40:48-59. doi:10.1016/j. chiabu.2014.10.024

136. Vaillancourt-Morel MP, Dugal C, Poirier Stewart R, et al. Extradyadic sexual involvement and sexual compulsivity in male and female sexual abuse survivors. J Sex Res. 2016;53(4-5):614-625. doi:10.1080/00224499.2015.1061633

137. M-P V-M, Godbout N, Bédard MG, Charest É, Briere J, Sabourin S. Emotional and sexual correlates of child sexual abuse as a function of self-definition status. Child Maltreat. 2016;21(3):228-238. doi:10.1177/1077559516656069

138. Vaillancourt-Morel MP, Godbout N, Sabourin S, Briere J, Lussier Y, Runtz M. Adult sexual outcomes of child sexual abuse vary according to relationship status. J Marital Fam Ther. 2016;42(2):341-356. doi:10.1111/jmft.12154

139. Bifulco A, Bernazzani O, Moran PM, et al. The childhood experience of care and abuse questionnaire (CECA.Q): validation in a community series. Br J Clin Psychol. 2005;44(4):563-581. doi:10.1348/014466505X35344

140. Lewczuk K, Szmyd J, Skorko M, Gola M. Treatment seeking for problematic pornography use among women. J Behav Addict. 2017;6(4):445-456. doi:10.1556/2006.6.2017.063

141. Brown KW, Ryan RM. The benefits of being present: mindfulness and its role in psychological well-being. J Pers Soc Psychol. 2003;84(4):822-848. doi:10.1037/0022-3514.84.4.822

142. Fuss J, Lemay K, Stein DJ, et al. Public stakeholders' comments on ICD-11 chapters related to mental and sexual health. World Psychiatry. 2019;18:233-235. doi:10.1002/wps.20635

143. Potenza MN, Gola M, Voon V, Kor A, Kraus SW. Is excessive sexual behaviour an addictive disorder? Lancet Psychiatry. 2017;4(9):663-664. doi:10.1016/S2215-0366(17)30316-4

144. Gola M, Potenza MN. The proof of the pudding is in the tasting: data are needed to test models and hypotheses related to compulsive sexual behaviors. Arch Sex Behav. 2018;47(5):1323-1325. doi:10.1007/s10508-018-1167-x

145. Kowalewska E, Grubbs JB, Potenza MN, Gola M, Draps M, Kraus SW. Neurocognitive mechanisms in compulsive sexual behavior disorder. Curr Sex Health Rep. 2018;10(4):255-264. doi:10.1007/s11930-018-0176-z

146. Böthe B, Vaillancourt-Morel M-P, Bergeron S, Demetrovics Z. Problematic and non-problematic pornography use among LGBTQ adolescents: a systematic literature review. Curr Addict Rep. 2019;6(4):478-494. doi:10.1007/s40429-01900289-5

147. Sklenarik S, Potenza MN, Gola M, Astur RS. Approach bias for erotic stimuli among heterosexual female college students who use pornography. Addict Behav. 2020;108:106438. doi:10.1016/j. addbeh.2020.106438

148. Field M, Mogg K, Bradley BP. Craving and cognitive biases for alcohol cues in social drinkers. Alcohol Alcohol. 2005;40 (6):504-510. doi:10.1093/alcalc/agh213

149. Mechelmans DJ, Irvine M, Banca P, et al. Enhanced attentional bias towards sexually explicit cues in individuals with and without compulsive sexual behaviours. PLoS One. 2014;9(8): e105476. doi:10.1371/journal.pone.0105476
150. Kagerer S, Wehrum S, Klucken T, Walter B, Vaitl D, Stark R. Sex attracts: investigating individual differences in attentional bias to sexual stimuli. PLoS One. 2014;9(9):e107795. doi:10.1371/journal.pone.0107795

151. Prause N, Janssen E, Hetrick WP. Attention and emotional responses to sexual stimuli and their relationship to sexual desire. Arch Sex Behav. 2008;37(6):934-949. doi:10.1007/ s10508-007-9236-6

152. Stark R, Klein S, Kruse O, et al. No sex difference found: cues of sexual stimuli activate the reward system in both sexes. Neuroscience. 2019;416:63-73. doi:10.1016/j. neuroscience.2019.07.049

153. Sharma D, Albery IP, Cook C. Selective attentional bias to alcohol related stimuli in problem drinkers and non-problem drinkers. Addiction. 2001;96(2):285-295. doi:10.1046/j.13600443.2001.96228512.x

154. Fromberger P, Jordan $\mathrm{K}$, von Herder J, et al. Initial orienting towards sexually relevant stimuli: preliminary evidence from eye movement measures. Arch Sex Behav. 2012;41(4):919-928. doi:10.1007/s10508-011-9816-3

155. Carnes P. Out of the Shadows: Understanding Sexual addiction. Center City: Hazelden Publishing; 2001.

156. Reid RC, Meyer MD. Substance use disorders in hypersexual adults. Curr Addict Rep. 2016;3(4):400-405. doi:10.1007/ s40429-016-0124-9

157. Ferree MC. No Stones: Women Redeemed from Sexual Addiction. 2nd ed. Downers Grove, IL: InterVarsity Press; 2010.

158. Lloyd M, Raymond NC, Miner MH, Coleman E. Borderline personality traits in individuals with compulsive sexual behavior. Sex Addict Compulsivity. 2007;14(3):187-206. doi:10.1080/10720160701480337

159. MacLaren VV, Best LA. Nonsuicidal self-injury, potentially addictive behaviors, and the five factor model in undergraduates. Pers Individ Differ. 2010;49(5):521-525. doi:10.1016/j.paid.2010.05.019

160. Erez G, Pilver CE, Potenza MN. Gender-related differences in the associations between sexual impulsivity and psychiatric disorders. J Psychiatr Res. 2014;55:117-125. doi:10.1016/j. jpsychires.2014.04.009

161. Miner MH, Coleman E. Compulsive sexual behaviors and its relationship to risky sexual behavior. Sex Addict Compulsivity. 2013;20:127-138.

162. Sansone RA, Sansone LA. Sexual behavior in borderline personality: a review. Innov Clin Neurosci. 2011;8:14-18.

163. Harned MS, Pantalone DW, Ward-Ciesielski EF, Lynch TR, Linehan MM. The prevalence and correlates of sexual risk behaviors and sexually transmitted infections in outpatients with borderline personality disorder. J Nerv Ment Dis. 2011;199 (11):832-838. doi:10.1097/NMD.0b013e318234c02c

164. Tull MT, Gratz KL, Weiss NH. Exploring associations between borderline personality disorder, crack/cocaine dependence, gender, and risky sexual behavior among substance-dependent inpatients. Pers Disord Theory Res Treat. 2011;2(3):209-219. doi:10.1037/a0021878

165. Hurlbert DF, Apt CV, White LC. An empirical examination into the sexuality of women with borderline personality disorder. J Sex Marital Ther. 1992;18(3):231-242. doi:10.1080/00926239208403409

166. Adams LM, Stuewig JB, Tangney JP. Relation of borderline personality features to preincarceration HIV risk behaviors of jail inmates: evidence for gender differences? Pers Disord Theory Res Treat. 2015;7(1):40-49. doi:10.1037/per0000124

167. Sansone RA, Wiederman MW. Borderline personality symptomatology, casual sexual relationships, and promiscuity. Psychiatry. 2009;6(3):36-40. 
168. Sansone RA, Barnes J, Muennich E, Wiederman MW. Borderline personality symptomatology and sexual impulsivity. Int J Psychiatry Med. 2008;38(1):53-60. doi:10.2190/PM.38.1.e

169. Meade CS, Sikkema KJ. HIV risk behavior among adults with severe mental illness: a systematic review. Clin Psychol Rev. 2005;25(4):433-457. doi:10.1016/j.cpr.2005.02.001

170. Chen EY, Brown MZ, Lo TTY, Linehan MM. Sexually transmitted disease rates and high-risk sexual behaviors in borderline personality disorder versus borderline personality disorder with substance use disorder. J Nerv Ment Dis. 2007;195(2):125-129. doi:10.1097/01.nmd.0000254745.35582.f6

171. Crittenden PM, Ainsworth MD. Child Maltreatment and Attachment Theory. London, England: Cambridge University Press; 1989.

172. Styron T, Janoff-Bulman R. Childhood attachment and abuse: long-term effects on adult attachment, depression, and conflict resolution. Child Abuse Negl. 1997;21(10):1015-1023. doi:10.1016/S0145-2134(97)00062-8

173. Hildyard KL, Wolfe DA. Child neglect: developmental issues and outcomes. Child Abuse Negl. 2002;26(6-7):679-695. doi:10.1016/S0145-2134(02)00341-1

174. Adams KM, Donald W, Robinson KDW. Shame reduction, affect regulation, and sexual boundary development: essential building blocks of sexual addiction treatment. Sex Addict Compulsivity. 2001;8(1):23-44. doi:10.1080/10720160127559

175. Alexander PC. Application of attachment theory to the study of sexual abuse. $J$ Consult Clin Psychol. 1992;60(2):185. doi:10.1037/0022-006X.60.2.185

176. Creeden $\mathrm{K}$. The neurodevelopmental impact of early trauma and insecure attachment: rethinking our understanding and treatment of sexual behavior problems. Sex Addict Compulsivity. 2004;11 (4):223-247. doi:10.1080/10720160490900560

177. Schwartz MF. Sexual compulsivity as post-traumatic stress disorder: treatment perspectives. Psychiatr Ann. 1992;22 (6):333-338. doi:10.3928/0048-5713-19920601-11
178. Schwartz MF. Developmental psychopathological perspectives on sexually compulsive behavior. Psychiatr Clin North Am. 2008;31 (4):567-586. doi:10.1016/j.psc.2008.07.002

179. Perera B, Reece M, Monahan P, et al. Childhood characteristics and personal dispositions to sexually compulsive behavior among young adults. Sex Addict Compulsivity. 2009;16(2):131-145. doi:10.1080/10720160902905421

180. Opitz D, Tsytsarev S, Froh J. Women's sexual addiction and family dynamics, depression and substance abuse. Sex Addict Compulsivity. 2009;16(4):324-340. doi:10.1080/ 10720160903375749

181. Edger K. The lived experiences of Evangelical Christian men who self-identify as sexual addicts: an existential phenomenological study. Sex Addict Compulsivity. 2009;16(4):289-323. doi:10.1080/10720160903307882

182. Timberlake D, Meyer D, Hitchings S, et al. Sexually compulsive behaviors: implications for attachment, early life stressors, and religiosity. Sex Addict Compulsivity. 2016;23(4):361-373. doi:10.1080/10720162.2016.1189862

183. Zapf J, Greiner J, Carroll J. Attachment style and male sex addiction. Sex Addict Compulsivity. 2008;15(2):158-175. doi:10.1080/10720160802035832

184. Gilliland R, Blue Star J, Hansen B, et al. Relationship attachment styles in a sample of hypersexual patients. J Sex Marit Ther. 2015;41(6):581-592. doi:10.1080/0092623X.2014.958787

185. Slavin MN, Scoglio AAJ, Blycker GR, et al. Child sexual abuse and compulsive sexual behavior: a systematic literature review. Curr Addict Rep. 2020;7(1):76-88. doi:10.1007/s40429-02000298-9

186. Henrich J, Heine SJ, Norenzayan A. The weirdest people in the world? Behav Brain Sci. 2010;33(2-3):61-135. doi:10.1017/ S0140525X0999152X
Neuropsychiatric Disease and Treatment

\section{Publish your work in this journal}

Neuropsychiatric Disease and Treatment is an international, peerreviewed journal of clinical therapeutics and pharmacology focusing on concise rapid reporting of clinical or pre-clinical studies on a range of neuropsychiatric and neurological disorders. This journal is indexed on PubMed Central, the 'PsycINFO' database and CAS, and
Dovepress

is the official journal of The International Neuropsychiatric Association (INA). The manuscript management system is completely online and includes a very quick and fair peer-review system, which is all easy to use. Visit http://www.dovepress.com/testimonials.php to read real quotes from published authors. 